\title{
Analisis Faktor Yang Memengaruhi Kejadian Hipertensi Pada Suku Batak Di Wilayah Kerja Puskesmas Cikampak Kabupaten Labuhan Batu Selatan
}

\author{
Berliana Harianja ${ }^{*}$, Thomson P Nadapdap, Anto \\ S2 IImu Kesehatan Masyarakat, Institut Kesehatan Helvetia Medan \\ *Email : berlianaharianja@gmail.com
}

\begin{abstract}
ABSTRAK
Hipertensi atau tekanan darah tinggi merupakan masalah yang ditemukan pada masyarakat baik di negara maju maupun berkembang termasuk Indonesia.. Adapun tujuan Analisis faktor yang memengaruhi Kejadian Hipertensi pada Suku Batak di Wilayah Kerja Puskesmas Cikampak Kabupaten Labuhan Selatan. Jenis penelitian ini merupakan survei analitik dengan rancangan cross sectional study. Penelitian dilakukan di Puskesmas Cikampak, Kabupaten Labuhan Batu Selatan. Populasi dalam penelitian ini yaitu rata-rata kunjungan pasien sebanyak 48 orang pada bulan Oktober-November 2019. Sampel diperoleh dengan menggunakan total sampling. Untuk menganalisis data tersebut digunakan uji regresi logistik.. Berdasarkan hasil penelitian diketahui bahwa kejadian hipertensi berhubungan dengan umur $(p=0,033)$, pola makanan $(p=0,017)$, konsumsi kopi $(p=0,000)$. Berdasarkan hasil penelitian, dapat disimpulkan bahwa faktor-faktor yang berhubungan dengan kejadian hipertensi berhubungan dengan umur, pola makanan, konsumsi kopi. Sehingga adapun saran dalam penelitian ini diharapkan agar penderita hipertensi mengurangi konsumsi faktor-faktor yang berhubungan dengan kejadian hipertensi dan melakukan pemeriksaan rutin di Wilayah Kerja Puskesmas Cikampak Kabupaten Labuhan Selatan
\end{abstract}

Kata Kunci : : Umur, Pola Makanan, Konsumsi Kopi

\begin{abstract}
Hypertension or high blood pressure is a problem that is found in the community both in developed and developing countries including Indonesia. The purpose of the analysis of factors that influence the incidence of hypertension in the Batak in the working area of the Cikampak Public Health Center in Labuhan Selatan District. This type of research is an analytic survey with a cross sectional study design. The study was conducted at the Cikampak Community Health Center, Labuhan Batu Selatan Regency. The population in this study was an average of 48 patient visits in October-November 2019. Samples were obtained using total sampling. To analyze the data logistic regression test was used. Based on the results of the study note that the incidence of hypertension is related to age $(p=0.033)$, dietary patterns $(p=0.017)$, coffee consumption $(p=0,000)$. Based on the results of the study, it can be concluded that the factors associated with the incidence of hypertension are related to age, dietary patterns, coffee consumption. So that the suggestions in this study are expected that hypertension sufferers reduce theconsumption of factors related to the incidence of hypertension and carry out routine checks in the work area of the Cikampak Community Health Center in Labuhan Selatan District.
\end{abstract}

\section{Keywords : Age, Food Pattern, Coffee Consumption}

\section{PENDAHULUAN}

Hipertensi atau tekanan darah tinggi merupakan masalah yang sering ditemukan pada masyarakat baik di negara maju maupun berkembang termasuk Indonesia. Hipertensi merupakan suatu keadaan meningkatnya tekanan darah sistolik lebih dari sama dengan $140 \mathrm{mmHg}$ dan diastolik lebih dari sama dengan $90 \mathrm{mmHg}$. Hipertensi dapat diklasifikasikan menjadi dua jenis yaitu hipertensi primer atau esensial yang penyebabnya tidak diketahui dan hipertensi sekunder yang dapat disebabkan oleh penyakit ginjal, penyakit endokrin, penyakit jantung, dan gangguan anak ginjal. Hipertensi seringkali tidak menimbulkan gejala, sementara tekanan darah yang terus-menerus tinggi dalam jangka waktu lama dapat menimbulkan komplikasi. Oleh karena itu hipertensi perlu dideteksi dini dengan cara pemeriksaan tekanan darah secara berkala.

Menurut WHO, hipertensi merupakan salah satu penyebab nomor 1 (satu) diantara 7 kematian di dunia dan WHO juga mencatat bahwa hipertensi juga menjadi penyebab $45 \%$ kematian akibat serangan jantung dan 51\% akibat stroke diseluruh dunia. Dari 927 juta penderita hipertensi, sebanyak 333 juta 
penderita hipertensi berada di negara maju dan 639 juta penderita hipertensi di negara berkembang. Hipertensi merupakan faktor penting yang mempengaruhi hampir 1 miliar orang di seluruh dunia dan menyebabkan sekitar 7,1 juta kematian pertahun pada usia dewasa. Prevalensi hipertensi di dunia sebesar 26,4 persen yang terdiri dari populasi usia dewasa. ${ }^{2}$ Indonesia merupakan negara dengan peringkat kelima dalam hal kejadian hipertensi dikawasan Asia Tenggara yaitu sebanyak 15 persen dari seluruh penduduk.

Menurut Riset Kesehatan Dasar tahun 2018, prevalensi hipertensi di Sumatera Utara merupakan provinsi nomor 3 setelah Sumatera Barat dan Aceh, yang memiliki prevalensi tertinggi kasus hipertensi. Pengukuran dan termasuk kasus yang sedang minum obat anti hipertensi berdasarkan provinsi: Sumatera Barat mengkonsumsi obat anti hipertensi sebesar $31,2 \%$, Aceh $30,2 \%$ dan Sumatera Utara $26,3 \%{ }^{3}$

Kementerian Kesehatan (2018) menyatakan bahwa di Indonesia terjadi peningkatan prevalensi hipertensi dari $7,6 \%$ pada tahun 2013 menjadi 9,5\% di tahun 2018. Penyakit hipertensi dan komplikasinya merupakan peringkat kelima di Indonesia dari 10 besar penyebab kematian tertinggi terhitung dari 41.590 kematian sejak Januari sampai Desember $2016 .{ }^{4}$

Tingginya kasus hipertensi menarik untuk diteliti karena penyakit yang dikenal dengan "silent killer" ini tidak menunjukkan gejala awal tapi dapat menyebabkan penyakit jangka panjang dan komplikasi yang berakibat fatal. Selanjutnya kebanyakan masyarakat masih menganggap hipertensi adalah hal yang sepele, padahal melihat komplikasinya jika terjadi tekanan darah tinggi pada seseorang, bisa berujung pada kematian. ${ }^{5}$

Perubahan gaya hidup berkaitan dengan budaya, suku, pola asupan makanan. Prevalensi hipertensidari beberapa suku sebesar70,7\% responden ada pada suku Jawa, $72,7 \%$ responden ada pada suku Sunda, $60,9 \%$ responden ada pada suku Betawi, 55,6\% responden ada pada suku Batak dan $78,6 \%$ responden ada pada suku Minang. ${ }^{6}$

Sangadji dan Nurhayati menjelaskan bahwa suku Batak memiliki risiko yang besar terkena hipertensi yang erat hubungannya dengan pola makan dengan prevalensi sebesar $55,6 \%$. Suku batak dikenal masyarakat mempunyai pola makan konsumsi daging cukup tinggi. Selain pola konsumsi, kebiasaan lain dari suku batak yang mendukung peningkatan risiko terjadinya hipertensi adalah merokok. Fenomena ini disebabkan karena budaya hidup suku batak yang merupakan pekerja keras dan kurang keperdulian terhadap kebutuhan akan kesehatan serta di sisi lain adanya perubahan gaya hidup masyarakat secara global, seperti semakin mudahnya mendapatkan makanan siap saji membuat konsumsi sayuran segar dan serat berkurang, kemudian konsumsi garam, lemak, gula, dan kalori yang terus meningkat .

Upaya untuk menekan kejadian hipertensi ataupun komplikasi akibat hipertensi perlu dilakukan dengan pendekatan/modifikasi gaya hidup seperti: mengatur pola makan dengan membatasi asupan garam,lemak, alkohol, berhenti merokok, dan mengontrol berat badan, melakukan aktivitas fisik,istirahat dan tidur yang cukup. $^{8}$

Faktor-faktor yang mempengaruhi terjadinya hipertensi dibagi dalam dua kelompok besar yaitu faktor yang tidak dapat dikendalikanseperti jenis kelamin, umur, genetik, ras dan faktor yang dapat dikendalikanseperti pola makan, kebiasaan olah raga, konsumsi garam, kopi, alkohol dan stres. Untuk terjadinya hipertensi perlu peran faktor risiko tersebut secara bersama-sama (common underlying risk factor), dengan kata lain satu faktor risiko saja belum cukup menyebabkan timbulnya hipertensi. ${ }^{9}$

Berdasarkan survey awal yang dilaksanakan di Puskesmas Cikampak Kabupaten Labuhan Selatan, didapatkan data jumlah kunjungan penderita hipertensi sebanyak 603 orang pada tahun 2017 dan 853 orang pada tahun 2018. Berdasarkan wawancara yang dilakukan terhadap 5 orang pasien suku batak yang datang untuk mendapatkan pelayanan/pemeriksaan kesehatan ke Puskesmas Cikampak Kabupaten Labuhan Selatan atas gangguan kesehatan dengan hipertensi dideritanya, diketahui bahwa mereka memiliki riwayat kebiasaan pola makan yang banyak mengandung garam, kurang mengkonsumsi sayur, dan konsumsi daging yang cukup tinggi pada saat sebelum menderita penyakit hipertensi dan kebiasaan itu masih juga berlangsung hingga saat diwawancara karena hal tersebut dianggap hal yang biasa saja oleh pasien terhadap penyakitnya.

\section{BAHAN DAN METODE}

Penelitian ini menggunakan Jenis penelitian survei analitik dengan pendekatan crosssectional. Lokasi penelitian lakukan di Puskesmas Cikampak Kabupaten Labuhan Batu Selatan. Waktu Penelitian berlangsung mulai bulan Juni sampai dengan September 2019

Populasi dalam penelitian ini adalah seluruh pasien suku Batak penderita hipertensi yang datang untuk memeriksakan kesehatan dan mendapatkan pelayanan kesehatan di 
Puskesmas Cikampak, dengan rata-rata kunjungan pasien sebanyak 48 orang. Sedangkan sampel dalam penelitian ini adalah seluruh pasien suku Batak penderita hipertensi yang datang untuk memeriksakan kesehatan mendapatkan pelayanan kesehatan ke Puskesmas Cikampak (total sampling) dengan

HASIL

Analisis Data Univariat

Berdasarkan data yang diperoleh dari hasil penelitian dengan 48 responden dapat dilihat dalam tabel distribusi frekuensi sebagai berikut. jumlah sampel sebanyak 48 orang.

Tabel 1. Distribusi Karakteristik Responden Berdasarkan Pekerjaan, Jenis Kelamin, Pendidikan

\begin{tabular}{lrc}
\hline Pekerjaan & $\mathbf{F}$ & $\%$ \\
\hline Petani & 25 & 52,08 \\
Wiraswasta & 12 & 25,00 \\
PNS & 11 & 22,92 \\
\hline Jenis Kelamin & $\mathbf{F}$ & $\%$ \\
\hline Laki-laki & 15 & 31,25 \\
Perempuan & 33 & 68,75 \\
\hline Pendidikan & $\mathbf{F}$ & $\%$ \\
\hline SD & 7 & 14,58 \\
SMP & 13 & 27,08 \\
SMA & 18 & 35,50 \\
PT & 10 & 20,83 \\
\hline Total & $\mathbf{4 8}$ & $\mathbf{1 0 0}$ \\
\hline
\end{tabular}

Berdasarkan tabel 1 di atas, diketahui bahwa dari 48 responden, sebagian besar responden bekerja sebagai petani yaitu sebanyak 25 $(52,08 \%)$ responden, sedangkan responden lainnya bekerja sebagai wiraswasta yaitu sebanyak $12(25,00 \%)$ responden, PNS sebanyak $11(22,92)$ responden.

Dari 64 responden diketahui bahwa sebagian besar responden berjenis kelamin perempuan yaitu sebanyak 33 (68,75\%) responden sedangkan responden yang berjenis kelamin laki-laki sebanyak 15 (31,25\%) responden.

Dari 64 responden diketahui bahwa sebagian besar responden berpendidikan SMA yaitu sebanyak $18 \quad(35,50 \%)$ responden, sedangkan responden berpendidikan SD yaitu sebanyak 7 (14,58\%) responden, responden berpendidikan SMP yaitu sebanyak 13 $(27,08 \%)$ responden, responden berpendidikan PT yaitu sebanyak $10(20,83 \%)$ responden.

\section{Analisis Data Bivariat}

Untuk mengetahui analisis faktor yang memengaruhi kejadian hipertensi pada Suku Batak di Wilayah Kerja Puskesmas Cikampak Kabupaten Labuhan Selatan, dapat dilihat pada tabel

ini:

Tabel 2. Faktor Yang Memengaruhi Kejadian Hipertensi Pada Suku Batak Di Wilayah Kerja Puskesmas Cikampak Kabupaten Labuhan Selatan

\begin{tabular}{|c|c|c|c|c|c|c|c|}
\hline \multirow[t]{3}{*}{ Umur } & \multicolumn{6}{|c|}{ Kejadian Hipertensi } & \multirow[t]{2}{*}{$P$ Value } \\
\hline & \multicolumn{2}{|c|}{ Tidak } & \multicolumn{2}{|c|}{ Ya } & \multicolumn{2}{|c|}{ Total } & \\
\hline & $f$ & $\%$ & $f$ & $\%$ & $f$ & $\%$ & 0,033 \\
\hline Muda & 9 & 18,75 & 8 & 16,67 & 17 & 35,42 & \\
\hline Tua & 7 & 14,58 & 24 & 50,00 & 31 & 64,58 & \\
\hline Total & 16 & 33,33 & 32 & 66,67 & 48 & 100 & \\
\hline \multicolumn{8}{|l|}{ Pola Makan } \\
\hline Kurang bergizi & 5 & 10,42 & 4 & 8,33 & 9 & 18,75 & \multirow[t]{3}{*}{0.017} \\
\hline Bergizi & $\overline{11}$ & 22,91 & 28 & 58,34 & 39 & 81,25 & \\
\hline Total & 16 & 33,33 & 32 & 66,67 & 48 & 100 & \\
\hline \multicolumn{8}{|l|}{ Konsumsi Kopi } \\
\hline Sesuai takaran & 12 & 25,00 & 2 & 4,17 & $\overline{14}$ & 29,17 & \multirow[t]{3}{*}{0,000} \\
\hline Tidak sesuai takaran & 4 & 8,33 & 30 & 62,25 & 34 & 70,83 & \\
\hline Total & 16 & 33,33 & 32 & 66,67 & 48 & 100 & \\
\hline
\end{tabular}

Berdasarkan tabel 2. diketahui bahwa dari 48 responden yang diteliti, sebagian besar responden berumur tua sebanyak $31(64,58 \%)$ responden. Dari 31 (64,58\%) responden 
tersebut, ada sebanyak 7 (14,58\%) responden berumur tua dan tidak mengalami kejadian hipertensi dan sebanyak 24 (50,00\%) responden berumur tua dan mengalami

kejadian hipertensi. Berdasarkan hasil perhitungan uji statistik diperoleh nilai $p$ significancy yaitu 0,033 $<0,05$, sehingga dapat disimpulkan bahwa ada pengaruh umur terhadap kejadian hipertensi pada Suku Batak di Wilayah Kerja Puskesmas Cikampak Kabupaten Labuhan Selatan. Untuk pola makan yang bergizi dari 48 responden yang diteliti, sebagian besar responden memiliki pola makan bergizi sebanyak $39(81,25 \%)$ responden. Dari $39(81,25 \%)$ responden tersebut, ada sebanyak $11(22,91 \%)$ responden memilki pola makan bergizi dan tidak mengalami kejadian hipertensi dan sebanyak $28(58,34 \%)$ responden memilki pola makan bergizi dan mengalami kejadian hipertensi. Berdasarkan hasil perhitungan uji statistik diperoleh nilai $p$ significancy yaitu 0,017 $<0,05$, sehingga dapat disimpulkan bahwa ada pengaruh pola makan terhadap kejadian hipertensi pada Suku Batak di Wilayah Kerja
Puskesmas Cikampak Kabupaten Labuhan Selatan. Sedangkan kebiasaan mengkonsumsi kopi diketahui dari 48 responden yang diteliti, sebagian besar responden mengonsumsi kopi tidak sesuai takaran sebanyak $34 \quad(70,83 \%)$ responden. Dari 34 (70,83\%) responden tersebut, ada sebanyak $4(8,33 \%)$ responden mengonsumsi kopi tidak sesuai takaran dan tidak mengalami kejadian hipertensi dan

sebanyak $30 \quad(62,25 \%)$ responden mengonsumsi kopi tidak sesuai takaran dan mengalami kejadian hipertensi. Berdasarkan hasil perhitungan uji statistik diperoleh nilai $p$ significancy yaitu $0,000<0,05$, sehingga dapat disimpulkan bahwa ada pengaruh konsumsi kopi terhadap kejadian hipertensi pada Suku Batak di Wilayah Kerja Puskesmas Cikampak Kabupaten Labuhan Selatan

\section{Analisis Multivariat}

Adapun variable mana yang paling dominan memengaruhi kejadian hipertensi pada Suku Batak di Wilayah Kerja Puskesmas Cikampak Kabupaten Labuhan Selatan, dapat dilihat pada tabel

ini:

Tabel 3. Analisis Multivariat Variabel paling dominan memengaruhi kejadian hipertensi pada Suku Batak di Wilayah Kerja Puskesmas Cikampak Kabupaten Labuhan Selatan

\begin{tabular}{|c|c|c|c|c|}
\hline Variabel & B & P vlue & Exp(B)OR & $95 \% \mathrm{Cl}$ for $\operatorname{Exp}(\mathrm{B})$ \\
\hline Umur & 1,513 & 0,110 & 4,540 & $0,711-29,006$ \\
\hline Konsumsi kopi & 3,888 & 0,000 & 48,806 & $6,836-348,430$ \\
\hline
\end{tabular}

Berdasarkan tabel 3 diatas dapat dilihat bahwa analisis regresi logistik menghasilkan 1 (satu) variabel yang paling dominan dengan kejadian hipertensi pada Suku Batak di Wilayah Kerja Puskesmas Cikampak Kabupaten Labuhan Selatan dengan $p$ value $<0,05$, yaitu variabel konsumsi kopi signifikan 0,000 ( $p$ value $<0,05), \quad$ OR $=48,806(95 \% \mathrm{Cl}=6,836-$ 348,430 ) artinya responden yang mengonsumsi kopi tidak sesuai dengan takaran mempunyai peluang 48,806 kali mengalami kejadian hipertensi dibandingkan dengan responden yang mengonsumsi kopi sesuai takaran dengan nilai koefisien B yaitu 3,888 bernilai positif, maka semakin tinggi pula kejadian hipertensi pada Suku Batak di Wilayah Kerja Puskesmas Cikampak Kabupaten Labuhan Selatan.

\section{PEMBAHASAN}

\section{Hubungan Umur dengan Kejadian Hipertensi Pada Suku Batak di Wilayah Kerja Puskesmas Cikampak Kabupaten Labuhan Selatan}

Berdasarkan hasil penelitian diketahui bahwa dari 48 responden yang diteliti, sebagian besar responden berumur tua sebanyak 31 $(64,58 \%)$ responden. Dari 31 (64,58\%) responden tersebut, ada sebanyak 7 (14,58\%) responden berumur tua dan tidak mengalami kejadian hipertensi dan sebanyak 24 (50,00\%) responden berumur tua dan mengalami kejadian hipertensi. Berdasarkan hasil perhitungan uji statistik diperoleh nilai $p$ significancy yaitu $0,033<0,05$, sehingga dapat disimpulkan bahwa ada hubungan umur dengan kejadian hipertensi pada Suku Batak.

Menurut Suhadjono, saat ini penderita hipertensi di dunia sekitar 1 miliar orang. Menariknya, ada hubungan antara umur dan penyakit tekanan darah ini. Semakin tinggi usianya yaitu 60 tahun ke atas maka semakin banyak yang alami hipertensi. Bahkan, pada usia 40 tahun ke atas dan semakin bertambah usianya maka semakin bertambah kemungkinan hipertensi. Sedangkan pada kaum dewasa muda, kata dia, jarang menderita penyakit ini dimana tekanan darahnya kurang dari $120 / 80 \mathrm{mmHg}$. Apalagi individu berumur < 30 tahun ditemukan mengalami penyakit hipertensi tanpa adanya faktor lain seperti obesitas, maka harus dicari tahu penyebabnya. Kemungkinan hipertensi ini disebabkan genetik atau penyakit bawaan keturunan. ${ }^{10}$

Hubungan Pola Makan Dengan Kejadian Hipertensi Pada Suku Batak di Wilayah 


\section{Kerja Puskesmas Cikampak Kabupaten Labuhan Selatan}

Berdasarkan hasil penelitian diketahui bahwa dari 48 responden yang diteliti, sebagian besar responden memiliki pola makan bergizi sebanyak $39(81,25 \%)$ responden. Dari 39 $(81,25 \%)$ responden tersebut, ada sebanyak 11 $(22,91 \%)$ responden memilki pola makan bergizi dan tidak mengalami kejadian hipertensi dan sebanyak $28(58,34 \%)$ responden memilki pola makan bergizi dan mengalami kejadian hipertensi. Berdasarkan hasil perhitungan uji statistik diperoleh nilai $\mathrm{p}$ significancy yaitu $0,017<0,05$, sehingga dapat disimpulkan bahwa ada hubungan pola makan dengan kejadian hipertensi pada Suku Batak

Kebanyakan masyarakat di wilayah kerja puskesmas Cikampak Kabupaten Labuhan

Batu Selatan mengonsumsi garam yang berlebih pada saat memasak yaitu $3 \times /$ hari, ikan laut, ikan tawar dan ikan asin atau teri yang asin karena banyak mengandung garam. Garam mengandung $40 \%$ sodium dan $60 \%$ klorida. Orang yang peka pada sodium lebih mudah meningkat sodiumnya, yang menimbulkan retensi cairan dan peningkatan tekanan darah. ${ }^{10}$

Garam berhubungan erat dengan terjadinya tekanan darah tinggi, gangguan pembuluh darah ini hampir tidak ditemui pada suku pedalaman yang asupan garamnya rendah. Jika asupan garam kurang dari 3 gram dalam sehari prevalensi hipertensiakan menurun, tetapi jika asupan garam 5-15. gram perhari, prevalensinya akan meningkat $15-20 \%{ }^{11}$ Garam mempunyai sifat menahan air. Mengonsumsi garam yang berlebih atau makanan yang diasinkan dapat menaikkan tekanan darah. Oleh sebab itu sebaiknya jumlah garam yang dikonsumsi harus dibatasi. $^{12}$

Berdasarkan kebiasaan masyarakat di wilayah kerja puskesmas Cikampak Kabupaten Labuhan Batu Selatan sangat senang mengonsumsi gula untuk membuat teh atau makan lain dalam sehari-hari. Gula tersebut jika dikonsumsi berlebih dapat meningkatkan berat badan. Kelebihan berat badan memberikan hubungan buruk pada tekanan darah, Penderita obesitas berisiko 2-6 kali lebih besar untuk terserang hipertensi dibandingkan orang dengan berat badan yang normal. Sedangkan kafein banyak terdapat pada kopi, teh dan minuman bersoda. Kopi dan teh jika dikonsumsi melebihi batas normal dalam penyajian akan mengakibatkan hipertensi. ${ }^{13}$

Hal Ini sejalan dengan penelitian andria dengan judul "Hubungan Antara Perilaku Olahraga, Stress dan pola makan dengan tingkat hipertensi pada lanjut usia di Posyandu
Lansia Kelurahan Gebang Putih Kecamatan Sukolilo Kota Surabaya" Hipertensi yang sering terjadi pada lansia adalah hipertensi sitolik yaitu jika tekanan sistolik $\geq 140 \mathrm{mmHg}$ dan tekanan diastolik $<90 \mathrm{mmHg}^{11}$

\section{Hubungan Konsumsi Kopi Dengan Kejadian Hipertensi Pada Suku Batak di Wilayah Kerja Puskesmas Cikampak Kabupaten Labuhan Selatan}

Berdasarkan tabel hasil penelitian diketahui bahwa dari 48 responden yang diteliti, sebagian besar responden mengonsumsi kopi tidak sesuai takaran sebanyak $34 \quad(70,83 \%)$ responden. Dari $34 \quad(70,83 \%)$ responden tersebut, ada sebanyak $4(8,33 \%)$ responden mengonsumsi kopi tidak sesuai takaran dan tidak mengalami kejadian hipertensi dan

sebanyak $30 \quad(62,25 \%)$ responden mengonsumsi kopi tidak sesuai takaran dan mengalami kejadian hipertensi. Berdasarkan hasil perhitungan uji statistik diperoleh nilai $p$ significancy yaitu $0,000<0,05$, sehingga dapat disimpulkan bahwa ada pengaruh konsumsi kopi terhadap kejadian hipertensi pada Suku Batak di Wilayah Kerja Puskesmas Cikampak Kabupaten Labuhan Selatan. Serta diketahui juga mayoritas masyarakat suku batak di wilayah kerja puskesmas tersebut sangat gemar mengonsumsi kopi kental dan pahit khususnya dipagi hari dan malam hari, Kopi juga dikonsumsi pada saat makan siang sebagai pendamping nasi. Ada beberapa penelitian yang telah membuktikan bahwa kafein dalam kopi dapat menyebabkan lonjakan tekanan darah sesaat setelah minum kopi. Kafein sendiri diyakini dapat merangsang kelenjar adrenal untuk melepaskan adrenalin lebih banyak. Hal ini bisa mengakibatkan peningkatan tekanan darah. Selain itu, kafein juga membuat diameter pembuluh darah mengecil, sehingga turut berkontribusi terhadap naiknya tekanan darah.

Menurut Martiani dengan judul penelitian Faktor Risiko Hipertensi Ditinjau Dari Kebiasaan Minum Kopi (Studi Kasus di Wilayah Kerja Puskesmas Ungaran pada Bulan JanuariFebruari 2012)" Kebiasaan minum kopi dilihat dari jenis kopi, frekuensi, kekentalan, dan lamanya minum kopi yang ditanyakan langsung dengan kuesioner, Hasil OR subjek yang minum kopi $\geq 5$ cangkir per hari kopi $(p=1,000$ $\mathrm{OR}=1,27$, IK 95\%:0,08-21,10) lebih rendah dibanding subjek yang minum kopi 1-2 cangkir per hari $(p=0,017 \quad O R=4,12$, IK 95\%:1,2213,39), walaupun secara statistik tidak bermakna. OR subjek minum kopi 3-4 cangkir per hari $(p=1,000$; OR=0,95; IK 95\%:0,20-4,57) lebih rendah dibanding subjek yang tidak minum kopi, walaupun secara statistik tidak 
bermakna. Subjek yang mengkonsumsi kopi 12 cangkir per hari, meningkatkan risiko hipertensi 4,11 kali lebih tinggi ( $p=0,017$; $\mathrm{OR}=4,11 ; \quad$ IK95\%:1,22-13,93) dibandingkan subjek yang tidak minum kopi.

\section{KESIMPULAN DAN SARAN}

1. Ada hubungan umur dengan kejadian hipertensi pada Suku Batak di Wilayah Kerja Puskesmas Cikampak Kabupaten Labuhan Selatan $(p=0,033)$.

2. Ada hubungan pola makan dengan kejadian hipertensi pada Suku Batak di Wilayah Kerja Puskesmas Cikampak Kabupaten Labuhan Selatan $(p=0,017)$.

3. Ada hubungan konsumsi kopi dengan kejadian hipertensi pada Suku Batak di Wilayah Kerja Puskesmas Cikampak Kabupaten Labuhan Selatan $(p=0,000)$

Adapun saran dalam penelitian ini diharapkan agar penderita hipertensi terlebih bagi orang tua agar mengurangi konsumsi faktor-faktor yang berhubungan dengan kejadian hipertensi dan melakukan pemeriksaan rutin di Wilayah Kerja Puskesmas Cikampak Kabupaten Labuhan Selatan

\section{DAFTAR PUSTAKA}

1. P. SR. dan W. Hipertensi Esensial, IImu Penyakit Dalam Jilid 11,. Jakarta: FK-UI; 2009.

2. Organization WHO. A global brief on hypertension: silent killer, global public health crisis: World Health Day 2013. World Health Organization; 2013.

3. Kementerian Kesehatan, Penelitian B, Kesehatan P. Hasil Utama RISKESDAS 2018. Jakarta [ID] Balitbangkes Kementeri Kesehat. 2018;

4. Kemenkes RI. Hipertensi. Infodatin Pusat Data dan Informasi Kementrian kesehatan RI. 2018; (Hipertensi):1-7.

5. Fitriani A. Gambaran Hipertensi dan hubungan dengan Kegemukan, Riwayat Hipertensi Orang Tua, Status Menopause,
Faktor Sosial-Demografi, dan Faktor Pola Hidup pada Anggota Majelis Taklim AlAmin Cilandak, Jakarta Selatan Tahun 2012. Skripsi Peminatan Gizi Kesehat Masyarakat Fak Kesehat Masyarakat Univ Indones. 2012;

6. Siregar CT. Pengalaman Pasien Hipertensi Primer Suku Minang Yang Menjalani Perawatan Di Rumah. Ners Journal Keperawatan. 2016;12(1):48-66

7. Sangadji N. Hipertensi pada Pramudi Bus Transjakarta di PT Bianglala Metropolitan tahun 2013. BIMKMI. 2014;6.

8. Indonesia DKR. Pedoman teknis penemuan dan tatalaksana penyakit

hipertensi. Jakarta Direktorat Pemberantasan Penyakit dan Penyehatan Lingkung Kementerian Kesehatan Republik Indonesia. 2003;

9. Indonesia DKR. Pedoman teknis penemuan dan tatalaksana penyakit

hipertensi. Jakarta Direktorat Pemberantasan Penyakit dan Penyehatan Lingkung Kementerian Kesehatan Republik Indonesia. 2006;

10. C B. Kiat Jantung Sehat. Bandung: Kaifa; 2002. 44-218 p.

11. Andria KM. Hubungan antara perilaku olahraga, stres dan pola makan dengan tingkat hipertensi pada lanjut usia di Posyandu Lansia Kelurahan Gebang Putih Kecamatan Sukolilo Kota Surabaya. Jurnal Promkes. 2013;1(2):111-7

12. Rachmawati YD. Hubungan antara Gaya Hidup dengan Kejadian Hipertensi pada Usia Dewasa Muda di Desa Pondok Kecamatan Nguter Kabupaten Sukoharjo. 2013;

13. Martiani A, Lelyana R. Faktor Risiko Hipertensi Ditinjau Dari Kebiasaan Minum Kopi (Studi Kasus di Wilayah Kerja Puskesmas Ungaran pada Bulan JanuariFebruari 2012). Diponegoro University; 2012 